\title{
Linsitinib (OSI-906) modulates brain energy metabolism and seizure activity in the lithium-pilocarpine rat model
}

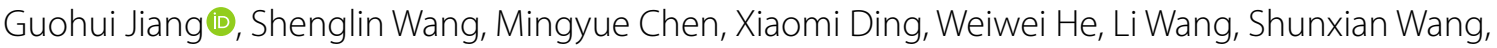 \\ Juming Yu and Xiaoming Wang*
}

\begin{abstract}
Background: Epileptic seizure is a process of energy accumulation, bursting, and depletion accompanied by the production, spread, and termination of epileptic discharges. The energy required for a seizure is mainly provided through mitochondrial production of ATP. Mitochondrial diseases often lead to epileptic seizures, and energy depletion caused by seizures can lead to mitochondrial dysfunction. The energy metabolism has become a key target for treatment of epileptic diseases.

Method: The effect of OSI-906, an insulin receptor (IR)/ insulin-like growth factor 1 receptor (IGF-1R) inhibitor, on behaviors and electroencephalographic activity in the lithium-pilocarpine rats were tested. ${ }^{18} \mathrm{~F}$-FDG positron emission tomography (PET)/ computed tomography (CT) was performed to detect the relative whole-brain glucose uptake values. Electron microscopy was performed to observe the ultrastructure of neuronal and mitochondrial damage. The changes in blood glucose at different time points before and after the intervention were tested and the effects of OSI906 on IR/IGF-1R and downstream Akt signaling in the context of seizures were evaluated.

Results: The OSI-906 treatment applied 3 days before the pilocarpine-induced seizures significantly reduced the seizure severity, prolonged the seizure latency and decreased the EEG energy density. MicroPET/CT revealed that $50 \mathrm{mg} /$ $\mathrm{kg}$ of OSI-906 inhibited the ${ }^{18} \mathrm{~F}-\mathrm{FDG}$ glucose uptake after epileptic seizures, suggesting that OSI-906, through inhibiting IR/IGF-1R and the downstream AKT signaling, may regulate the excessive energy consumption of the epileptic brain. The OSI-906 treatment also reduced the mitochondrial damage caused by epileptic seizures.
\end{abstract}

Conclusion: The IR/IGF-1R inhibitor OSI-906 can significantly reduce the sensitivity and severity of pilocarpineinduced seizures by inhibiting the IR/IGF-1R and the downstream Akt signaling pathway.

Keywords: Epilepsy, Mitochondria, Energy metabolism, Insulin receptor, IGF-1 receptor, Akt signaling

\section{Background}

Epilepsy is one of the most common diseases of the nervous system, with an electrophysiological feature of highly synchronous abnormal discharges of neurons, which leads to clinical syndromes of transient brain dysfunction

*Correspondence: wangxm238@163.com

Department of Neurology, Affiliated Hospital of North Sichuan Medical College, Institute of Neurological Diseases, North Sichuan Medical

College, Nanchong, China
$[1,2]$. An epileptic seizure represents a process of energy accumulation, bursting and depletion, accompanied by the production, spread and termination of epileptic discharges that consequently lead to neuronal injury [3, 4]. Early experimental studies demonstrated that the cellular adenosine triphosphate (ATP) content in brain is reduced before the onset of epileptic activity [5, 6]. Previous studies have suggested that the depletion of ATP, which is produced and supplied by the mitochondria, triggers original author(s) and the source, provide a link to the Creative Commons licence, and indicate if changes were made. The images or other third party material in this article are included in the article's Creative Commons licence, unless indicated otherwise in a credit line to the material. If material is not included in the article's Creative Commons licence and your intended use is not permitted by statutory regulation or exceeds the permitted use, you will need to obtain permission directly from the copyright holder. To view a copy of this licence, visit http://creativecommons.org/licenses/by/4.0/. The Creative Commons Public Domain Dedication waiver (http://creativeco mmons.org/publicdomain/zero/1.0/) applies to the data made available in this article, unless otherwise stated in a credit line to the data. 
chronic spontaneous seizures, and the excessive energy depletion during seizures also promotes the progression of seizures $[7,8]$.

Insulin and insulin-like growth factor-1 (IGF-1) are multipotent bioactive substances found in almost all tissues. In the brain they are involved in energy and glucose homeostasis and affect neuronal survival, learning, memory, and injury repair $[9,10]$. Disorders of the insulin and insulin receptor (IR) system in the central nervous system (CNS) play vital roles in the occurrence and development of nerve injury, neurodegenerative diseases, and neuropsychiatric diseases [11-13]. Previous studies have found that the expression of IR is significantly increased in the anterior temporal neocortex of patients with refractory epilepsy [14]. We have also detected increased levels of IGF-1 and IGF-1 receptor (IGF-1R) in the temporal lobe and hippocampus of various epileptic models. Intracerebroventricular injection of neuroprotective doses of IGF-1 in other neurological diseases may promote epileptic seizures and the development of epilepsy by activating IGF-1R and the downstream signaling [15].

Linsitinib (OSI-906) is an oral small-molecule inhibitor that has demonstrated strong anti-tumor effects in tumor cell models in vitro, by selectively inhibiting the autophosphorylation of both human IGF-1R and IR [16]. OSI-906 reduces the tumor volume and prolongs the survival of patients by inhibiting the proliferation, survival, and energy metabolism of tumor cells through the phosphatidylinositol 3-kinase (PI3K)/ protein kinase B (Akt) signaling pathway $[17,18]$. However, the effect of OSI906 in epilepsy has not been studied.

In this study we evaluated the effects of OSI-906 on the IR/IGF-1R and the downstream PI3K/AKT signaling, the energy metabolism level, and the mitochondrial morphology in the brain of a rat model with lithium-pilocarpine-induced epileptic seizures, as well as the effect on lithium-pilocarpine-induced epileptic seizures in the rat model.

\section{Materials and Methods}

\section{Animals}

Male Sprague-Dawley rats (weighting 180-200 g) were housed at the Laboratory Animal Center of North Sichuan Medical College (NSMC 201,810), under standard temperature, humidity and circadian rhythm conditions with ad libitum access to food and water. All animal experiments were performed in accordance of the Animal Research Committee of North Sichuan Medical College and were approved by the Chinese Animal Welfare Act for the use and care of laboratory animals.

\section{Experimental groups}

The commonly used doses of OSI-906 in in vivo interventional studies in rodents range $25-75 \mathrm{mg} / \mathrm{kg}$ [16]. Therefore, we divided the animals into the vehicle group, $25 \mathrm{mg} / \mathrm{kg}$ OSI-906 group, $50 \mathrm{mg} / \mathrm{kg}$ OSI-906 group, and $75 \mathrm{mg} / \mathrm{kg}$ OSI-906 group $(n=18$ in each group, 5 for electrophysiological recording and 13 for behavioral recording and related testing). OSI-906 was diluted to a volume of $2 \mathrm{ml}$ with tartaric acid solution and was administered by gavage once daily for 3 consecutive days, while the vehicle group was given $2 \mathrm{ml}$ of tartaric acid solution only (Fig. 1).

\section{Animal model of epilepsy}

The pilocarpine model, which reproduces most of the seizure phenotypes, was used in this study. The electroencephalogram (EEG) data and the neuropathological characteristics of temporal lobe epilepsy were recorded as described previously $[19,20]$. In brief, the rats were injected with lithium chloride (Sigma, USA; $127 \mathrm{mg} /$ $\mathrm{kg}$, i.p.) $20 \mathrm{~h}$ and atropine sulfate $(1 \mathrm{mg} / \mathrm{kg}$, i.p. $) 30 \mathrm{~min}$ before the first pilocarpine $(35 \mathrm{mg} / \mathrm{kg}$, i.p.) administration. If rats did not develop epileptic seizures $30 \mathrm{~min}$ after the first injection of pilocarpine, the dose of pilocarpine was increased by $20 \%$ every $10 \mathrm{~min}$ until the development of level-4-5 seizures. The total number

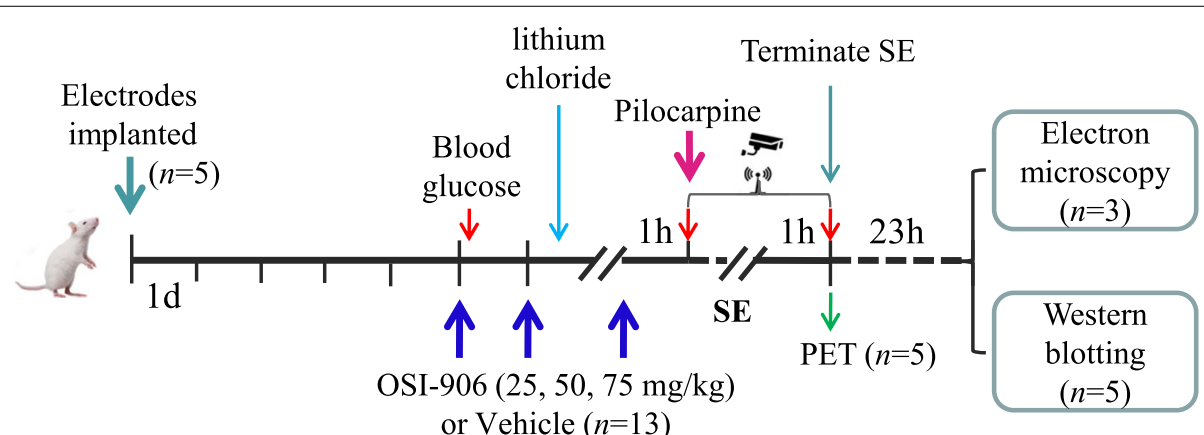

Fig. 1 Schematic of experimental design 
of pilocarpine injections was limited to five per animal. After 60 min of status epilepticus (SE), diazepam (DZP, $10 \mathrm{mg} / \mathrm{kg})$, phenobarbital $(25 \mathrm{mg} / \mathrm{kg})$, and atropine sulfate $(1 \mathrm{mg} / \mathrm{kg})$ were injected intraperitoneally to terminate the convulsive seizures [21]. The seizure activity was scored according to the Racine's standard criteria [22]. Only rats that achieved recurrent seizures of stage 4 to 5 were used for subsequent tests.

\section{Surgical procedures and electrophysiological recordings}

The rat was anesthetized with chloral hydrate $(350 \mathrm{mg} /$ $\mathrm{kg}$, i.p.) and flurbiprofen axetil was injected $(5 \mathrm{mg} / \mathrm{kg}$, Beijing Tide Pharmaceutical Co., Ltd., Beijing) through a tail vein to relieve pain. Then, the rat was placed in a stereotaxic apparatus. A microwire array $(4 \times 4$ array of platinum-iridium alloy electrodes, each $25 \mu \mathrm{m}$ in diameter) was implanted in the right dorsal hippocampus (anterior-posterior $-3.6 \mathrm{~mm}$, medial-lateral $2.8 \mathrm{~mm}$, dorsal-ventral $-3.5 \mathrm{~mm}$ ) one week before recording and fixed with dental cement as described by Paxinos and Watson (2007). Local field potentials (LFPs) were preamplified $(\times 1000)$, filtered $(0.1-1000 \mathrm{~Hz})$, and digitized at $4 \mathrm{kHz}$ using an OmniPlex ${ }^{\circledR} \mathrm{D}$ Neural Data Acquisition System (Plexon, Dallas, TX). Electrophysiological recordings were made with the direct current-coupled head stages, and all recordings were referenced to the two ground screws.

\section{Analysis of electrophysiological data}

We employed NeuroExplorer ${ }^{\circledR}$ (v4.0; Plexon, USA) and MATLAB software (v7.1, R2009a; MathWorks, Inc., Natick, MA) to calculate the electrophysiological data. A fast Fourier transform was applied to power spectrum analysis after digital filtering with $0.1-1000 \mathrm{~Hz}$ bandpass. The frequency spectra of continuous variables and the neuronal rate histograms were obtained by the power spectral density analysis of our previous method [23]. We calculated the high-frequency discharge energy during seizures including ripples $(80-200 \mathrm{~Hz})$. The MATLAB function in the Signal Processing Toolbox was used to compute the power of ripple oscillators and magnitudesquared coherence. MATLAB and GraphPad Prism softwares (GraphPad Software, Inc., La Jolla, CA) were used for statistical analysis and image processing.

\section{Blood glucose monitoring}

Blood glucose was measured by a Roche glucometer (Roche, Germany) in venous blood from the tail vein before treatment, $1 \mathrm{~h}$ after the first intragastric administration of vehicle or OSI-906, $1 \mathrm{~h}$ after gastric perfusion of OSI-906 on the third day, and $1 \mathrm{~h}$ after the epileptic seizures. Animals were fasted for more than $12 \mathrm{~h}$ before OSI-906 intervention. As we found that $75 \mathrm{mg} / \mathrm{kg}$ of
OSI-906 treatment significantly increased blood glucose and aggravated epileptic seizures, and the mortality rate reached $100 \%$ during the acute epileptic seizure, subsequent relevant tests were not completed in this group.

\section{${ }^{18}$ F-FDG-microPET imaging}

MicroPET is a non-invasive imaging technique that is often used to record and analyze the correlation between neural function changes and brain energy metabolism in small animals. To determine the effect of IR/IGF-1R inhibitor OSI-906 on glucose uptake in the brain after the epileptic seizures, a ${ }^{18}$ F-FDG-PET-CT scanner (SiemensInveon Multi-Modality System, Erlangen, Germany) was used to detect cerebral glucose uptake at $1 \mathrm{~h}$ after the pilocarpine-induced seizures. First, the rats were fixed and injected with ${ }^{18} \mathrm{~F}$-FDG $(500 \mu \mathrm{Ci})$ through the tail vein as a tracer to detect the relative cerebral glucose metabolism rate. Thirty minutes later, they were anesthetized with isoflurane (induction period: $5 \%$ isoflurane $+1 \mathrm{~L} /$ min $\mathrm{O}_{2}$, maintenance period: $1 \%$ isoflurane $+1 \mathrm{~L} / \mathrm{min} \mathrm{O}_{2}$ ) using an inhaled anesthesia system. Then the rats were scanned in the prone position in a three-dimensional model for $8 \mathrm{~min}$ (field of vision: $85.62 \mathrm{~mm} \times 125.58 \mathrm{~mm}$ ), and the static PET data were collected for $7 \mathrm{~min}$. The CT signal was mainly used for anatomical description and attenuation correction of ${ }^{18}$ F-FDG-PET images.

\section{PET data analysis}

The imaging data were imported into the Inveon Research Workplace software for analysis, and data were collected in the form of lists. The cerebral metabolism rate was reconstructed using the maximum posterior probability algorithm, with a pixel size of $0.4 \times 0.4 \times 1.2$ $\mathrm{mm}^{3}$. Glucose metabolism in the brain was evaluated as the whole-brain average standard uptake values (SUV) using the following equation: SUV $=\mathrm{Ct} / \mathrm{ID} * \mathrm{Wt} . \mathrm{Ct}(\mathrm{MBq} /$ $\mathrm{cm}^{3}$ ), in which $\mathrm{Ct}$ indicates the activity concentration after the decay correction of the measured brain region; ID $(\mathrm{mCi})$ indicates the injection dose of ${ }^{18} \mathrm{~F}$-FDG; and $\mathrm{Wt}$ $(\mathrm{kg})$ represents the weight of the rat [24]. We recorded the maximum and the mean SUV values of normal rats, as well as SUV value $1 \mathrm{~h}$ post-seizure, and that post the OSI-906 intervention (OSI-906 $50 \mathrm{mg} / \mathrm{kg}+\mathrm{SE}$ ).

\section{Projection electron microscopy}

The ultrastructural changes of nucleus and mitochondria in rat hippocampal neurons were observed by projection electron microscopy in the vehicle control, SE, and OSI$906+$ SE groups $(n=3)$. All animals were deeply anesthetized with $10 \%$ chloral hydrate and then injected with fresh normal saline to the heart. The rat was cardinally perfused with a mixture of glutaraldehyde (2\%) and paraformaldehyde for heart reperfusion and tissue fixation, 
and then the brain was collected. The hippocampal tissue was isolated immediately, and the CA1 area of the hippocampus was cut into $1 \mathrm{~mm}^{3}$ pieces. Three specimens were taken from each rat and fixed in $4 \%$ glutaraldehyde solution. The fixed tissues were sent to the electron microscope room of Chongqing Medical University for unified specimen preparation. Images under projection electron microscopy (JEOL JEM-1400, Japan) were captured.

\section{Western blotting}

Hippocampal tissues were collected $24 \mathrm{~h}$ after pilocarpine administration and stored at $-80{ }^{\circ} \mathrm{C}$ for western blotting. The tissues were homogenized in lysate buffer containing phosphatase and protease inhibitors (Sigma, St. Louis, MO), centrifuged (Sigma-Aldrich, USA) and the supernatant collected. The total protein concentration was determined with the BCA protein assay (Beyotime Institute of Biotechnology, China). The total protein samples were loaded at $40 \mu \mathrm{g} / \mathrm{lane}$ for sodium dodecyl sulfate polyacrylamide gel ( $5 \%$ spacer gel; $10 \%$ separating gel) electrophoresis, followed by electro-transfer onto polyvinylidene fluoride membranes (Millipore).

The membranes were blocked with 5\% non-fat milk at room temperature for $120 \mathrm{~min}$, then incubated with antip-IR (Tyr1361), anti-IR, anti-pIGF-1R (Tyr1135), antiIGF-1R, anti-p-AKT (Ser473), anti-AKT or anti- $\beta$-actin (1:500-1000, Cell Signaling Technology, Inc Boston, MA, USA) antibody for $16 \mathrm{~h}$ at $4{ }^{\circ} \mathrm{C}$. After TBST wash, the membranes were incubated with goat anti-rabbit IgG (1:5000, Cell Signaling Technology, Inc Boston, MA) for $1 \mathrm{~h}$. Electrochemiluminescence system (Bio-Rad, CA, USA) was used to visualize the protein bands with a chemiluminescence kit (Biosharp, Beijing, China). Blot intensities were analyzed with QuantityOne software (Bio-Rad Laboratories, version 4.6.2, Hercules, CA).

\section{Statistical analysis}

All data were analyzed using the SPSS 19.0 statistical software (IBM Corp., Armonk, NY), and the values are expressed as mean \pm SEM. All data were tested for normality and if non-normal, a non-parametric test was used. One-way analysis of variance (ANOVA) was used for comparisons between more than two groups; the Student's $t$-test was used for comparison between groups of multiple samples, and the Bonferroni test was used for post-test analysis. The Wilcoxon rank-sum test (MannWhitney U-test) was performed to compare two groups of ordinal variables. The $\mathrm{K}-\mathrm{W}$ test was used to compare the classification data of multiple groups, and Fisher's exact test was also used to compare classification variables between two groups. $P<0.05$ was considered as statistically significant.

\section{Results}

OSI-906 at $50 \mathrm{mg} / \mathrm{kg}$ significantly reduced the severity of SE and prevented mortality during SE

We first observed the effect of OSI-906 on the latency of class 4-5 seizures induced by pilocarpine. Compared with the vehicle control group, the $50 \mathrm{mg} / \mathrm{kg}$ OSI-906 group showed a significantly prolonged latency of the pilocarpine-induced seizures (Bonferroni's multiple comparisons test, $P=0.028$ ) and a decreased rate of firstdose seizures of stage 4-5 (Fisher's exact test, $P=0.03$ ). In addition, the $25 \mathrm{mg} / \mathrm{kg}$ OSI-906 group did not show significant difference in the above indicators compared to the control group $(P>0.05)$, while the $75 \mathrm{mg} / \mathrm{kg}$ OSI906 group had opposite effects to the $50 \mathrm{mg} / \mathrm{kg}$ OSI-906 group (Table 1 and Fig. 2). At last, 7 rats in the vehicle group, 7 rats in the $25 \mathrm{mg} / \mathrm{kg}$ OSI-906 group and 6 rats in the $50 \mathrm{mg} / \mathrm{kg}$ OSI-906 group developed recurrent stage 4-5 seizures. They were used for subsequent electron microscopy and western blotting assay $(n=5)$. Rats that underwent LFP recordings were added for electron microscopy detection (the side without electrodes).

\section{Effect of OSI-906 on hippocampal epileptiform discharge in pilocarpine-induced seizures}

We recorded LFPs in hippocampal CA1 using in vivo multichannel microfilament electrodes to investigate the effect of OSI-906 on the excitability of the hippocampal neural circuit during pilocarpine-induced seizures. Compared to the vehicle control group, the $50 \mathrm{mg} / \mathrm{kg}$ OSI-906 intervention group showed a significantly prolonged latency of epileptic discharge, a significantly shortened discharge duration, and a reduced average

Table 1 Effect of OSI-906 on acute epileptic seizures $(n=13)$

\begin{tabular}{lllll}
\hline Group & Latency of seizure $(\mathbf{m i n})$ & $\begin{array}{l}\text { Seizure onset rate at } \\
\text { the first dose }\end{array}$ & Cumulative seizure rate & Mortality \\
\hline Vehicle & $28.55 \pm 2.76$ & $7 / 13(53.85 \%)$ & $11 / 13(84.62 \%)$ & $4 / 13(30.77 \%)$ \\
OSI-906 25 & $31.30 \pm 4.01$ & $6 / 13(46.15 \%)$ & $10 / 13(76.92 \%)$ & $3 / 13(23.08 \%)$ \\
OSI-906 50 & $41.33 \pm 12.79^{*}$ & $1 / 13(7.69 \%)^{*}$ & $6 / 13(46.15 \%)$ & $0 / 13(0 \%)$ \\
OSI-906 75 & $14.46 \pm 14.08^{* *}$ & $13 / 13(100 \%)^{*}$ & $13 / 13(100 \%)^{*}$ & $13 / 13(100 \%)^{* *}$ \\
\hline
\end{tabular}

Note: The dosing unit of OSI-906 is mg/kg. Compared with the vehicle group, ${ }^{*} P<0.05$ and ${ }^{* * P}<0.01$ 
a

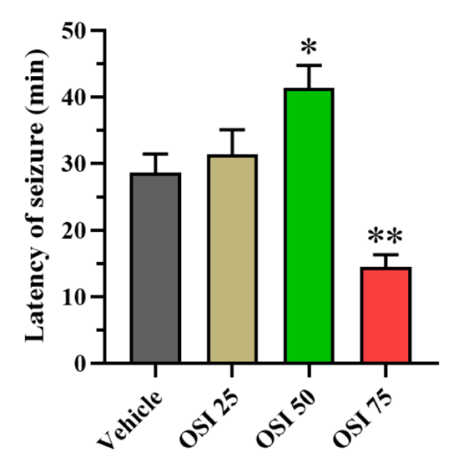

b

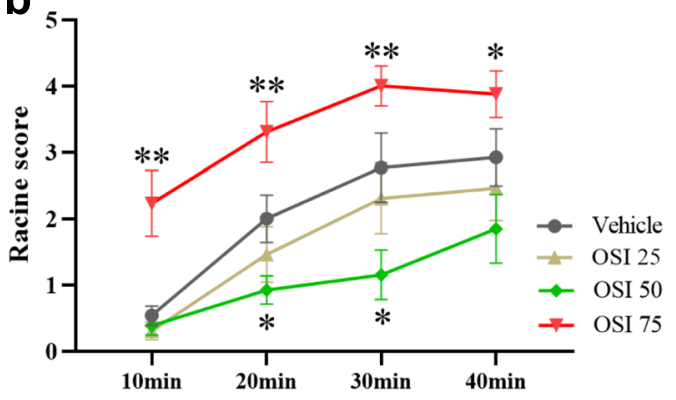

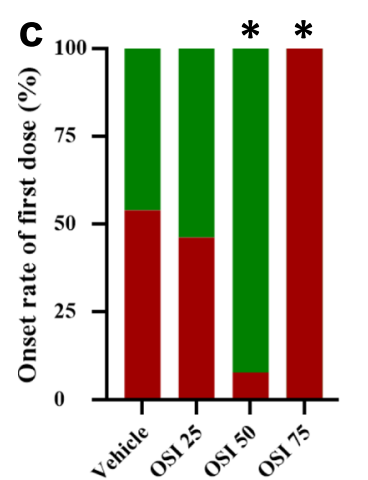
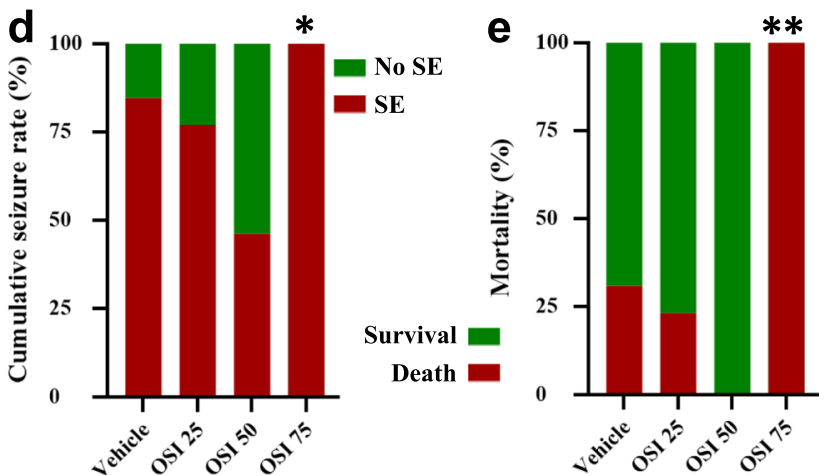

Fig. 2 Effects of OSI-906 on acute epileptic seizures. (a) 50 mg/kg OSI-906 extended the seizure latency. (b) 50 mg/kg OSI-906 significantly reduced Racine score, but $75 \mathrm{mg} / \mathrm{kg}$ OSI-906 aggravated the severity of seizures. (c\&d) First-dose and cumulative stage $4-5$ seizure rates. (e) Effects of OSI-906 on mortality in acute rats. Bars represent mean \pm SEM ( $n=13$ for each group). ${ }^{*} P<0.05$ and ${ }^{* *} P<0.01$ compared to the control group

power spectrum of electrical activity (Bonferroni's multiple comparisons test, $P=0.001,0.013,0.0001$, respectively, Fig. 3c, d). However, there was no such significant difference between the $25 \mathrm{mg} / \mathrm{kg}$ OSI-906 intervention group and the vehicle group. The mortality was $30.77 \%$ in the control group, and zero in the $50 \mathrm{mg} / \mathrm{kg}$ OSI-906 group. Surprisingly, the death rate of animals was $100 \%$ after pilocarpine-induced epileptic seizures in the $75 \mathrm{mg} /$ kg OSI-906 group.

\section{Effect of OSI-906 on blood glucose}

The $25 \mathrm{mg} / \mathrm{kg}$ and $50 \mathrm{mg} / \mathrm{kg}$ groups had similar changes of blood glucose in comparison to the control group at different time points of treatment, suggesting that the effect of OSI-906 on epileptic seizures was not directly through the regulation of blood glucose. OSI-906 at $75 \mathrm{mg} / \mathrm{kg}$ significantly increased the blood glucose level $1 \mathrm{~h}$ after the third gastric perfusion and $1 \mathrm{~h}$ after the epileptic seizures, compared to the control group (ANOVA and post hoc analysis using the Bonferroni method, $P<0.01$ and $P<0.0001$, respectively, $n=5$; Fig. 4 ). Considering that hyperglycemia or hypoglycemia may affect the mitochondrial function and epileptic seizures [25], the $75 \mathrm{mg} / \mathrm{kg}$ OSI-906 group was excluded from subsequent experiments to exclude possible confounding factors. The specific blood glucose values are shown in Table 2.

\section{OSI-906 inhibits excessive energy consumption} of the brain caused by seizures

Compared to the normal control group, the average whole-brain SUV value was significantly increased $1 \mathrm{~h}$ after the pilocarpine-induced recurrent epileptic seizures $(1.63 \pm 0.14$ vs $1.98 \pm 0.34, n=5, P=0.003$, Fig. 5$)$. In the $50 \mathrm{mg} / \mathrm{kg}$ OSI-906 group, the average whole-brain SUV value $1 \mathrm{~h}$ after the epileptic seizures was $1.77 \pm 0.21$, significantly lower than the SE group $(P=0.013)$. However, it was unclear whether the reduced SUVs were attributed to the inhibition of seizures or were because OSI-906 lowered the glucose uptake.

\section{Ultrastructural changes of the nucleus and mitochondria in neurons}

The mitochondria are responsible for aerobic respiration and energy transformation, and make most of the cell's supply. Repeated or continuous epileptic seizures rely on mitochondrial function. Meanwhile, excessive energy consumption caused by epileptic seizures will destroy the mitochondrial structure and function, leading to persistent 

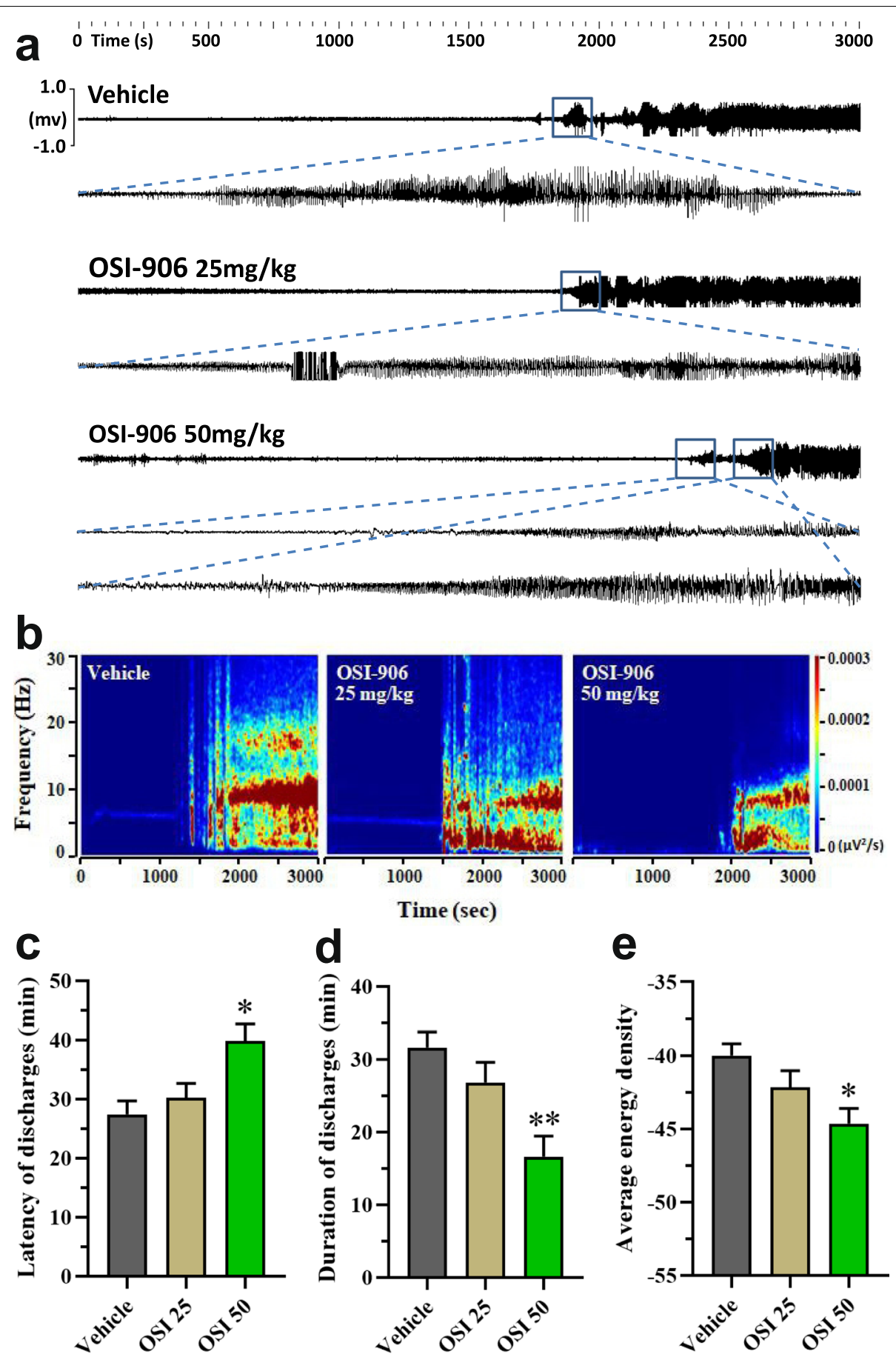

Fig. 3 Effects of OSI-906 on epileptic discharge in acute epileptic seizures. (a) Effects of OSI-906 on hippocampal electrical activity (the X-axis is $60 \mathrm{~min}$ and the Y-axis is \pm 1.0 millivolts). (b) Corresponding power spectrograms of each group. (c-e) $50 \mathrm{mg} / \mathrm{kg}$ OSI-906 shortened the latency of epileptic discharge, and reduced the duration of epileptic discharge and the mean energy density value of brain electrical activity. Data are shown as mean \pm SEM. ${ }^{*} P<0.05$ and ${ }^{* *} P<0.01$ compared to the control group; $n=5$ each group

disorders of brain energy metabolism in patients with epilepsy, thus resulting in a vicious cycle [4, 26]. Therefore, brain energy metabolism and mitochondria are key targets in epilepsy research and treatment strategies. Transmission electron microscopy revealed that the normal rat hippocampal neurons had a clear outline, a large 

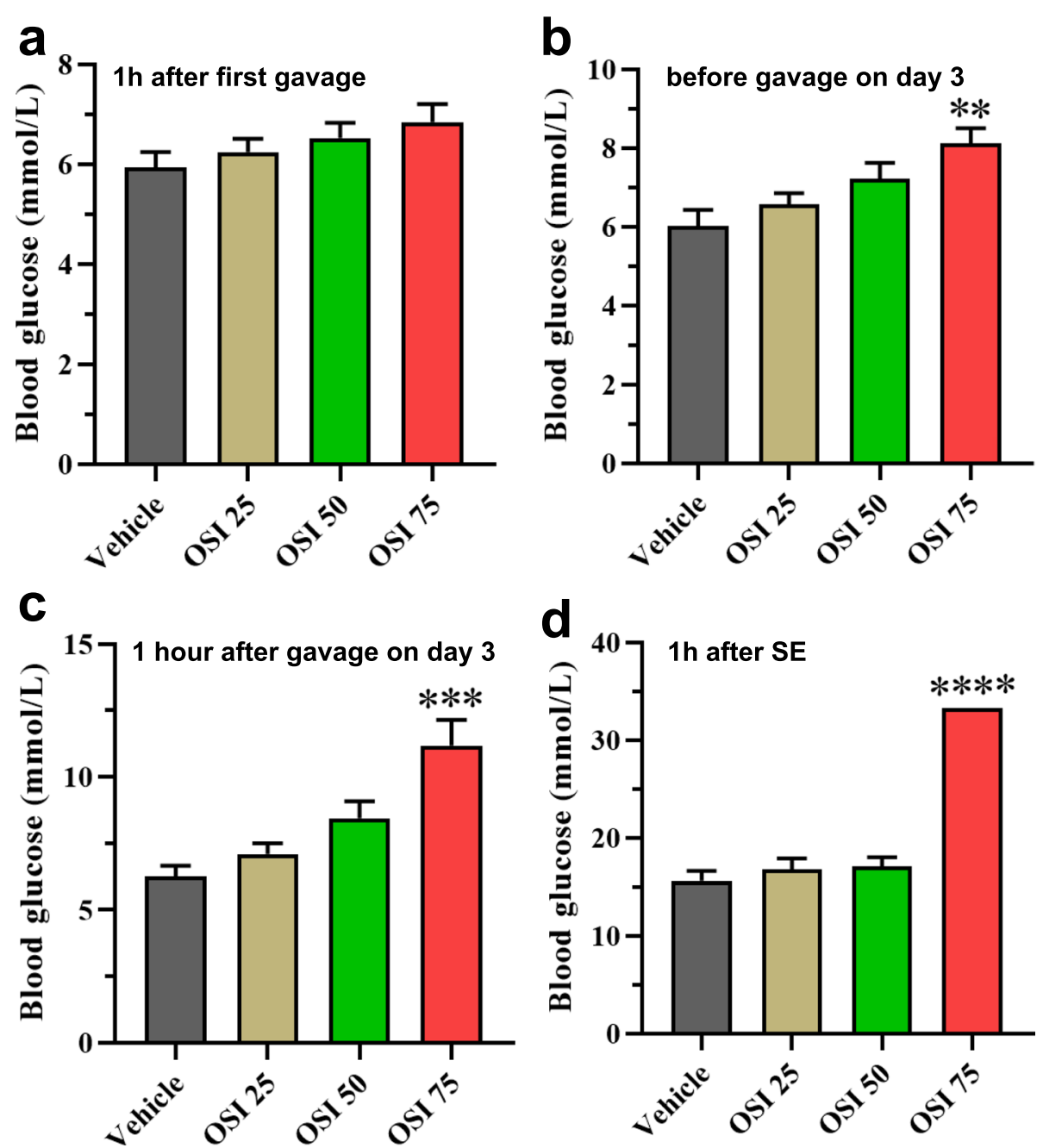

Fig. 4 Effect of OSI-906 treatment on blood glucose before and after the seizures. (a) Blood glucose level did not significantly change at $1 \mathrm{~h}$ after the first OSI-906 gavage, compared with the control group $(P>0.05)$. (b\&c) OSI-906 at $75 \mathrm{mg} / \mathrm{kg}$ significantly increased the blood glucose at fasting or $1 \mathrm{~h}$ after gavage on day 3. $P=0.0024$ and 0.0002 , respectively, vs the control, one-way ANOVA. (d) In the $75 \mathrm{mg} / \mathrm{kg}$ OSI-906 group, blood glucose levels were higher after the seizure compared with the control group. Data are shown as mean \pm SEM. ${ }^{* *} P<0.01,{ }^{* * *} P<0.001,{ }^{* * *} P<0.0001(n=5)$

and round nucleus, uniform chromatin, clear cytoplasm, clear and complete double-layer nuclear membrane at high magnification, and mitochondria with complete inner and outer membranes as well as cristae formed by innermembrane depression. At $24 \mathrm{~h}$ after the epileptic seizures, the mitochondrial cristae were disordered, shortened, and swollen. The cristae of mitochondria blurred, were broken, and disappeared, the matrix was swollen and vacuolated, and an autophagosome was formed. The nucleus of the neuron was shrunken and deeply stained, and the

Table 2 Effects of OSI-906 on blood glucose $(n=5)$

\begin{tabular}{lllcc}
\hline Groups & $\begin{array}{l}\text { Blood glucose } \mathbf{1} \mathbf{~ h} \text { after the } \\
\text { first OSI-906 (mmol/L) }\end{array}$ & $\begin{array}{l}\text { Blood glucose before gavage } \\
\text { on day } \mathbf{3}(\mathbf{m m o l} / \mathbf{L})\end{array}$ & $\begin{array}{l}\text { Blood glucose1 } \mathbf{~ h ~ a f t e r ~ g a v a g e ~} \\
\text { on day 3 (mmol/L) }\end{array}$ & $\begin{array}{l}\text { Blood glucose 1 } \mathbf{~} \\
\text { after SE (mmol/L) }\end{array}$ \\
\hline vehicle & $5.94 \pm 0.31$ & $6.02 \pm 0.48$ & $6.26 \pm 0.79$ & $15.60 \pm 1.09$ \\
OSI-906 $25 \mathrm{mg} / \mathrm{kg}$ & $6.24 \pm 0.49$ & $6.56 \pm 0.54$ & $7.10 \pm 0.84$ & $16.78 \pm 1.18$ \\
OSI-906 $50 \mathrm{mg} / \mathrm{kg}$ & $6.52 \pm 0.58$ & $7.22 \pm 1.20$ & $8.44 \pm 2.18$ & $17.04 \pm 1.44$ \\
OSI-906 $75 \mathrm{mg} / \mathrm{kg}$ & $6.84 \pm 0.90$ & $8.12 \pm 2.10^{* *}$ & $11.18 \pm 4.92^{* * *}$ & $\geqq 33.33^{* * * *}$ \\
\hline
\end{tabular}

${ }^{* *} P<0.01,{ }^{* * *} P<0.001$, and ${ }^{* * * *} P<0.0001$ vs the vehicle control group 

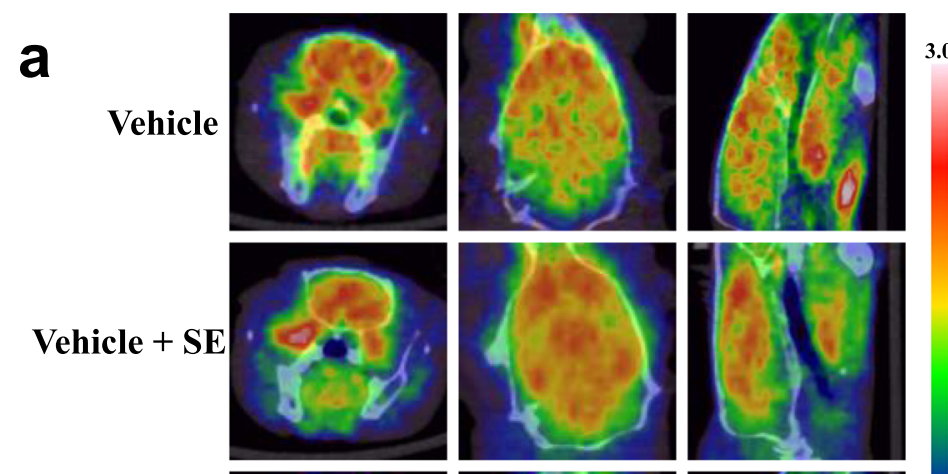

3.0
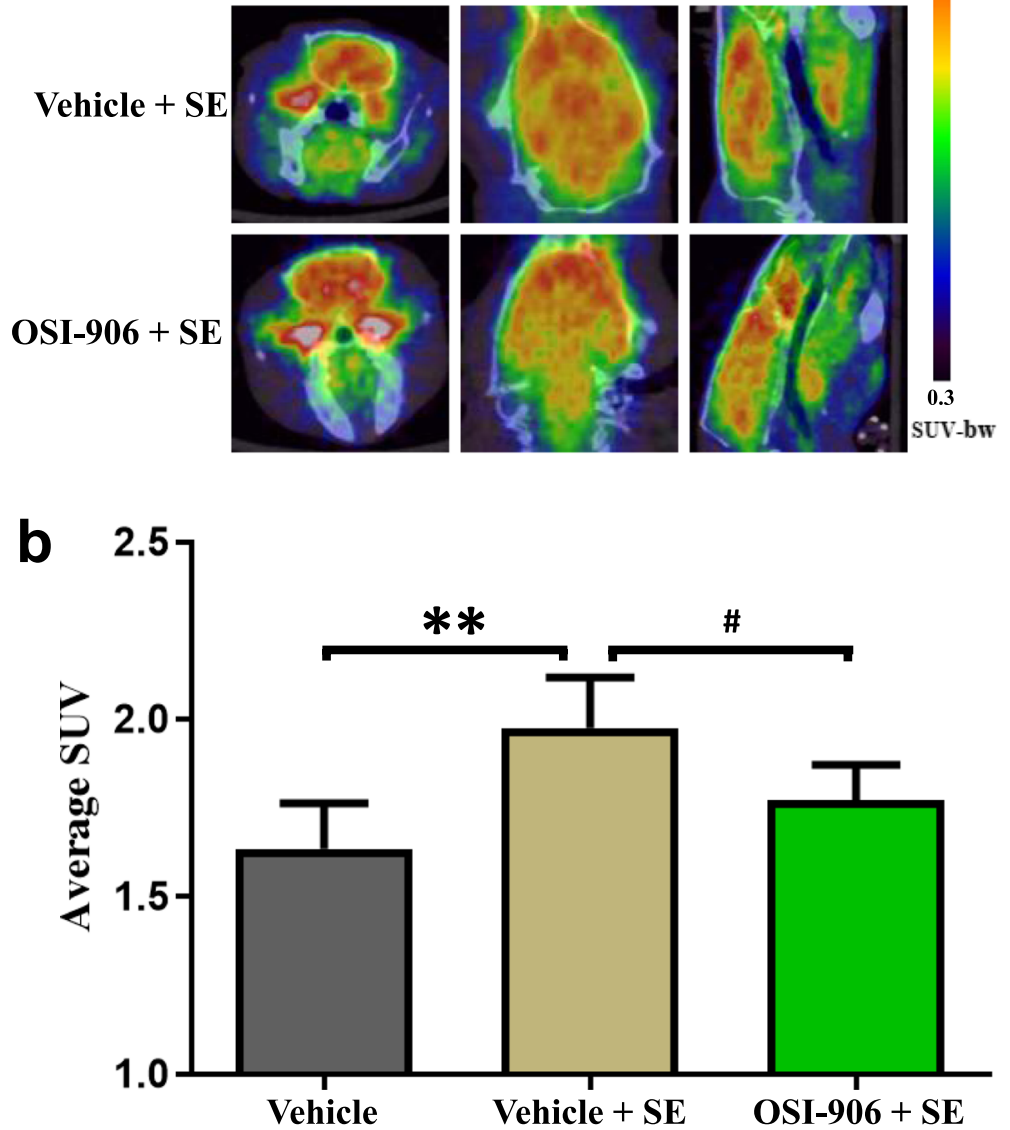

Fig. 5 OSI-906 decreased the glucose uptake $1 \mathrm{~h}$ after seizures. (a) ${ }^{18}$ F-FDG micro-PET/CT quantification of glucose metabolism in vivo. (b) Compared with the normal control group, the average whole-brain SUV value was significantly increased $1 \mathrm{~h}$ after pilocarpine-induced epileptic seizures. Treatment with $50 \mathrm{mg} / \mathrm{kg}$ of OSI-906 significantly reduced the value of glucose uptake in the brain $(n=5)$. Data are shown as mean \pm SEM. ${ }^{*} P<0.01,{ }^{\#} P<0.05$

chromatin in the nucleus was concentrated. Compared with the epilepsy model group, the $50 \mathrm{mg} / \mathrm{kg}$ OSI-906 intervention group showed less damage to the mitochondria and nucleus (Fig. 6).

\section{Effects of OSI-906 on IR/IGF-1R and Akt signaling}

As shown in Fig. 7, the pIR/IR, pIGF-1R/IGF-1R, and $\mathrm{p}-\mathrm{AKT} / \mathrm{AKT}$ ratios were prominently elevated at $24 \mathrm{~h}$ after the pilocarpine-induced seizures, compared to those in the vehicle group $(n=5$, ANOVA, $P<0.01)$. However, they were markedly suppressed in the $50 \mathrm{mg} / \mathrm{kg}$ OSI-906 group (Fig. 7, $P<0.05$ ), suggesting that $50 \mathrm{mg} / \mathrm{kg}$ of OSI-906 could inhibit the activation of IR/IGF-1R and the downstream AKT signaling pathways involved in the pilocarpineinduced seizures.

\section{Discussion}

In the present study, we showed that OSI-906 at $50 \mathrm{mg} /$ $\mathrm{kg}$ significantly reduced the susceptibility to and severity of seizures induced by pilocarpine (Table 1 \&Fig. 2). Synchronous EEG recording also showed that $50 \mathrm{mg} / \mathrm{kg}$ of OSI-906 significantly prolonged the latency of epileptic discharge, shortened the duration of discharge, and decreased the mean energy density of brain electrical activity (Fig. 3). However, OSI-906 at $75 \mathrm{mg} / \mathrm{kg}$ increased the blood glucose and aggravated seizures (Table 2, Fig. 4). As an increase or decrease of blood glucose can 


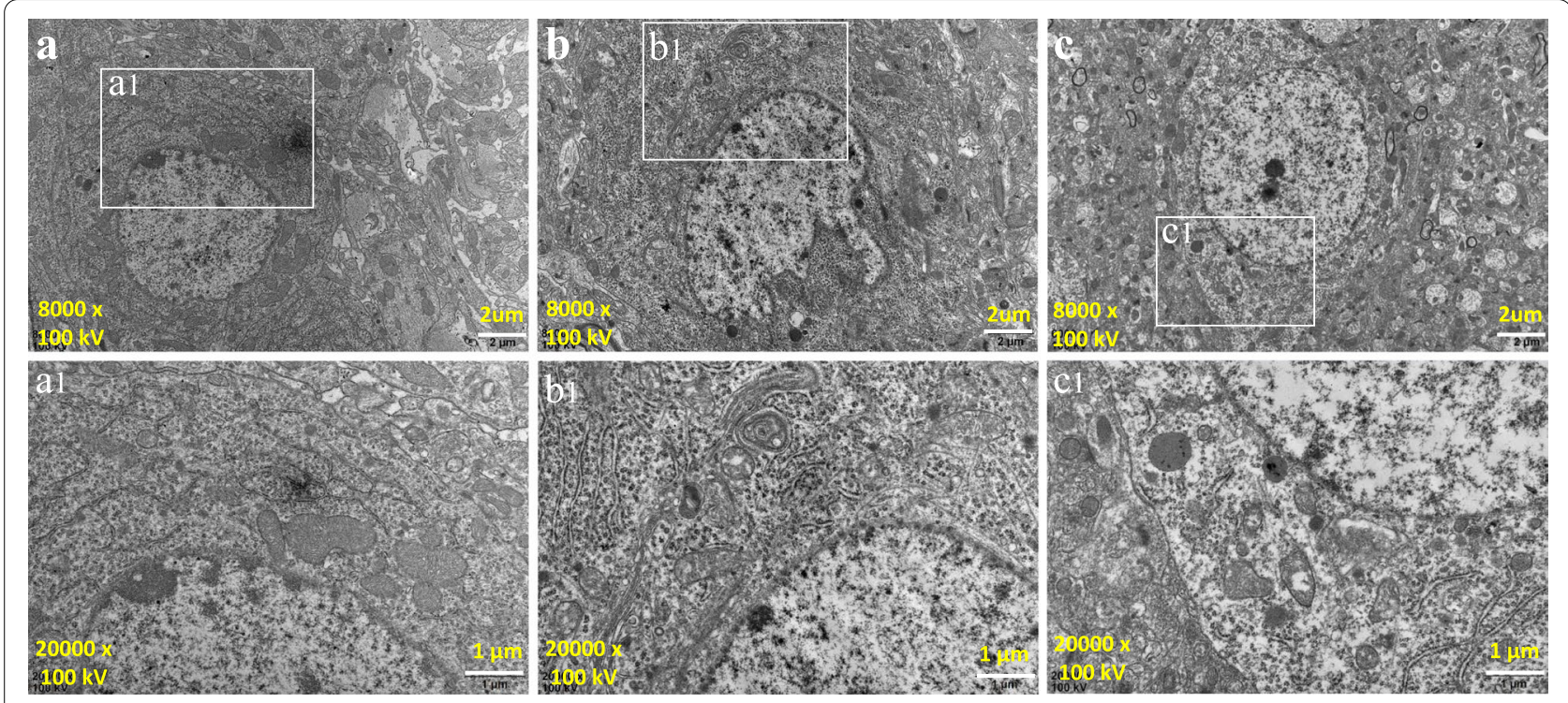

Fig. 6 Ultrastructural changes of nucleus and mitochondria in neurons. (a) Hippocampal neurons and mitochondria in control rats. (b) Ultrastructural changes of nuclei and mitochondria in hippocampal neurons. (c) Compared to the epilepsy model group, the $50 \mathrm{mg} / \mathrm{kg}$ OSI-906 group showed less damage to the mitochondria and nuclei. $\mathbf{a}, \mathbf{b}$ and $\mathbf{c}$ are magnified 8,000 times, and $\mathbf{a} \mathbf{1}, \mathbf{b} \mathbf{1}$ and $\mathbf{c} \mathbf{1}$ are magnified 20,000 times

affect the mitochondrial function and epileptic activity [25], this group of rats failed to complete the subsequent tests.

In a clinical study, OSI-906 was continuously given in a once- or twice-daily schedule in patients with advanced solid tumors [27]. In this study, the blood glucose increased after $75 \mathrm{mg} / \mathrm{kg}$ of OSI-906 application for 3 consecutive days, indicating a cumulative effect of OSI-906. However, there was no significant difference in blood glucose during single administration, and continuous dosing could better reflect the effect of homeostasis OSI-906 concentration on epileptic activity. The high dose of OSI-906 $(75 \mathrm{mg} / \mathrm{kg})$ inhibits IR/IGF-1R, resulting in increased blood glucose, which may be the main reason for the opposite outcome to that of $50 \mathrm{mg} / \mathrm{kg}$ OSI906. In addition, the blood glucose increased significantly in the vehicle group and in different dose groups of OSI906 after SE, which may be related to the stress response induced by SE. However, the specific mechanisms remain unclear.

The brain is a high-consumption organ, which constitutes only $2 \%$ of the human body weight, while consuming $20 \%$ to $25 \%$ of the energy supply in the body [28]. The brain energy metabolism has been shown as a key factor affecting the epileptic seizures, and may be an important target for epilepsy research and treatment [29].

Surprisingly, the ${ }^{18}$ F-FDG-PET scanning showed that $50 \mathrm{mg} / \mathrm{kg}$ of OSI-906 treatment significantly reduced the average whole-brain SUV value after seizures, possibly related to its inhibition of seizure activity (Fig. 5). During epileptic seizures, neurons are highly synchronized and discharge abnormally, which leads to the brain energy depletion. This excessive energy depletion depends on the mitochondrial oxidative phosphorylation to produce a large amount of ATP. Of note, energy depletion hinders glucose transport and oxidative metabolism and destroys the mitochondrial structure and function [4]. As a result, after the onset of epilepsy, ATP production is compromised, and pathological changes such as abnormal neuronal ion transport, disorders of neurotransmitter uptake and release, and blockade of protein signaling, may ultimately result in recurrent spontaneous epileptic seizures, namely, epileptogenesis [30, 31]. In addition, after longterm spontaneous seizures, significantly reduced glucose metabolism is observed in multiple brain regions, which can affect the neuronal function [32-34]. Hence, OSI-906 may inhibit the seizure activity through reduction of the glucose uptake in the brain and inhibition of excessive energy consumption of the brain caused by seizures.

We further found that the epileptic seizures resulted in changes in mitochondrial structure, including disordered and shortened cristae, partial mitochondrial swelling, mitochondrial ridge blurring, fracture and disappearance, matrix swelling, vacuolization, neuronal nuclear shriveling, and hyperchromatic concentration, which were improved by $50 \mathrm{mg} / \mathrm{kg}$ of OSI-906 (Fig. 6). As an alternative energy source, a ketogenic diet may be an effective treatment of epilepsy, which improves the 

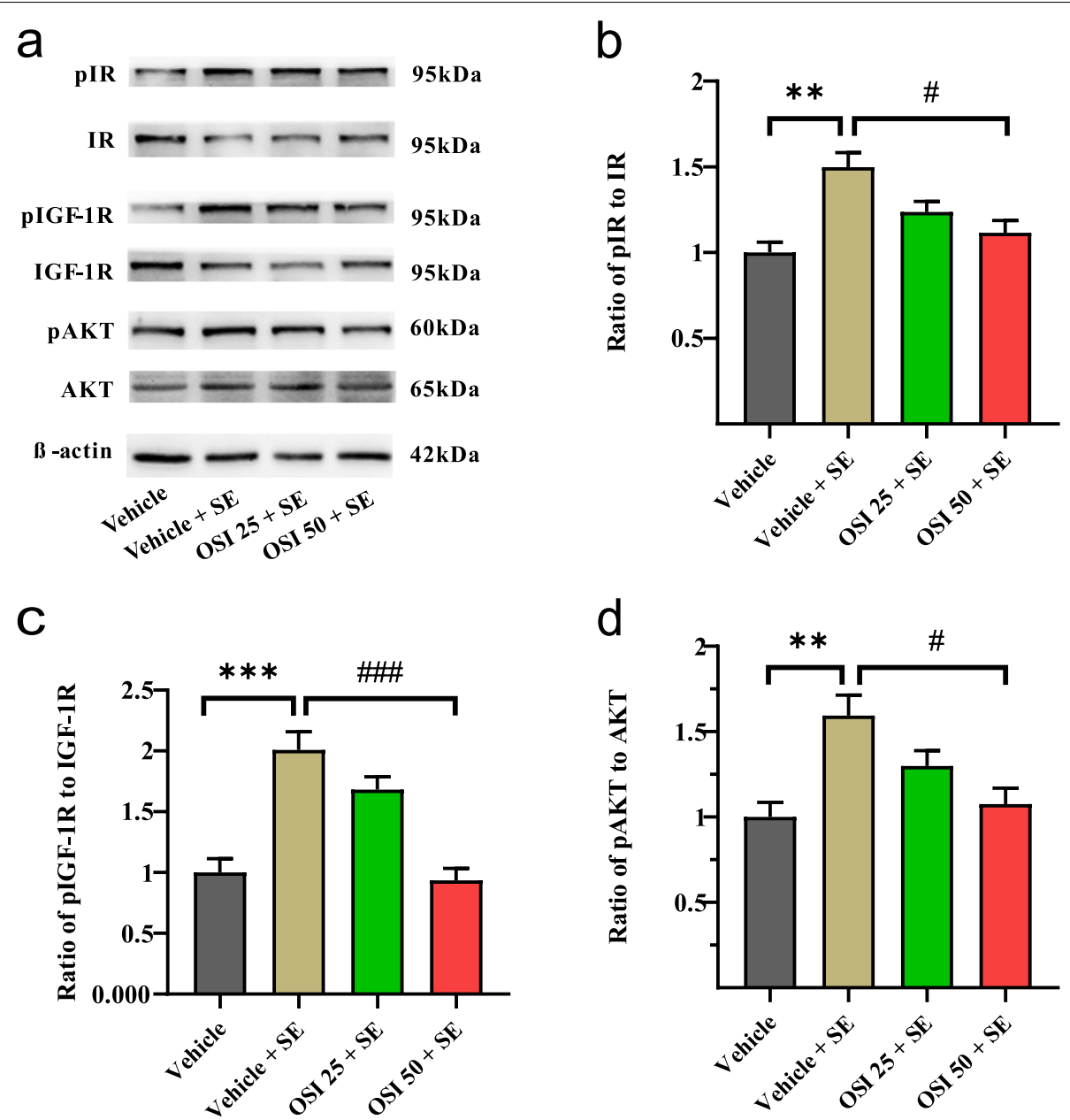

Fig. 7 Effects of OSI-906 on IR, IGF-1R and AKT signaling. (a) The representative bands of western blotting. (b-d) The pIR/IR, plGF-1R/IGF-1R, and $\mathrm{p}$-Akt/Akt ratios were significantly elevated at $24 \mathrm{~h}$ after pilocarpine-induced seizures, compared with those in the vehicle group. Compared to those in the seizure group, these ratios were markedly reduced in the $50 \mathrm{mg} / \mathrm{kg}$ OSI-906 group. Data are shown as mean $\pm S E M$. $n=5$, ANOVA, ${ }^{* *} P<0.01,{ }^{* * *} P<0.001,{ }^{\#} P<0.05,{ }^{\# \# \# P<0.001}$

neuronal damage caused by decreased energy metabolism in the brain during epileptic seizures [35-37]. Our study suggests that the inhibition of epileptic activity by $50 \mathrm{mg} / \mathrm{kg}$ of OSI-906 may restrain the excessive energy consumption of the brain by regulating the function of mitochondria and may have a protective effect on mitochondria in the context of epileptic seizures. In our behavioral and electrophysiological studies, we found that $50 \mathrm{mg} / \mathrm{kg}$ of OSI-906 significantly reduced the susceptibility to and severity of seizures.

The small molecule OSI-906 is a dual receptor inhibitor of IR/IGF-1R, which effectively and selectively inhibits the phosphorylation of IR and IGF-1R and has a strong anti-tumor effect in many types of cancer [38]. We found that $50 \mathrm{mg} / \mathrm{kg}$ of OSI-906 significantly inhibited the activation of IR, IGF-1R, and AKT signals after epileptic seizures (Fig. 7). We speculated that during the pilocarpine-induced epileptic status, OSI-906 inhibits the excessive energy intake and consumption in the brain, possibly through inhibiting the IR/IGF-1R and the downstream AKT signaling. More studies are needed to fully clarify the underlying mechanisms.

\section{Conclusion}

In conclusion, OSI-906 at $50 \mathrm{mg} / \mathrm{kg}$ inhibits the brain energy metabolism and epileptic activity during epileptic seizure, and has a protective effect on mitochondrial damage caused by epileptic seizure. OSI-906 at $50 \mathrm{mg} / \mathrm{kg}$ may inhibit epileptic seizures by inhibiting the IR/IGF$1 \mathrm{R}$ and the downstream AKT signaling. These results provide new evidence for the use of OSI-906 in the treatment of epileptic status. 


\begin{abstract}
Abbreviations
ATP: Adenosine triphosphate; CNS: Central nervous system; CT: Computed tomography; EEG: Electroencephalogram; IGF-1: Insulin-like growth factor-1; IR: Insulin receptor; IGF-1R: Insulin-like growth factor-1 receptor; i.p.: Intraperitoneal; LFPs: Local field potentials; PET: Positron emission tomography; SUV: Standard uptake values.
\end{abstract}

\section{Acknowledgements}

This work was supported by the National Natural Science Foundation of China (No. 81971220) and the Science and Postdoctoral Science Foundation of China (No. 20191964). We thank Drs. Y. Chen and Y. Zhao for their assistance in ${ }^{18} \mathrm{~F}-\mathrm{FDG}$-PET testing from the Department of Nuclear Medicine of Southwest Medical University.

\section{Authors' information}

Not applicable.

\section{Authors' contributions}

GHJ performed experiments and participated in data analysis and manuscript writing. SLW, MYC and XMD carried out animal experiments. WWH, LW and SXW participated in the study and analyzed the results. JMY and XMW supervised the design of the research. All authors approved the final manuscript.

\section{Funding}

This work was supported by the National Natural Science Foundation of China (No. 81971220) and the Science and Postdoctoral Science Foundation of China (No. 2019M653978).

\section{Availability of data and materials}

Not applicable.

\section{Declarations}

\section{Ethical approval and consent to participate}

All animal experiments were performed in accord with the Animal Research Committee of North Sichuan Medical College and were formally approved by the Chinese Animal Welfare Act for the use and care of laboratory animals.

\section{Consent for publication}

All authors have read and approved the publication of this manuscript.

\section{Competing interests}

The authors declare that there are no conflicts of interest for the present investigation.

Received: 21 June 2021 Accepted: 16 July 2021

Published online: 24 August 2021

\section{References}

1. Moshe SL, Perucca E, Ryvlin P, Tomson T. Epilepsy: new advances. Lancet. 2015;385:884-98.

2. Staley K. Molecular mechanisms of epilepsy. Nat Neurosci. 2015;18:367-72.

3. Wu Y, Liu D, Song Z. Neuronal networks and energy bursts in epilepsy. Neuroscience. 2015;287:175-86.

4. Zsurka G, Kunz WS. Mitochondrial dysfunction and seizures: the neuronal energy crisis. Lancet Neurol. 2015;14:956-66.

5. Cloix JF, Hevor T. Epilepsy, regulation of brain energy metabolism and neurotransmission. Curr Med Chem. 2009;16:841-53.

6. Kovac S, Abramov AY, Walker MC. Energy depletion in seizures: anaplerosis as a strategy for future therapies. Neuropharmacology. 2013;69:96-104

7. Malkov A, Ivanov Al, Buldakova S, Waseem T, Popova I, Zilberter M, et al. Seizure-induced reduction in glucose utilization promotes brain hypometabolism during epileptogenesis. Neurobiol Dis. 2018;116:28-38.
8. Rowley S, Patel M. Mitochondrial involvement and oxidative stress in temporal lobe epilepsy. Free Radic Biol Med. 2013;62:121-31.

9. Fernandez AM, Torres-Aleman I. The many faces of insulin-like peptide signalling in the brain. Nat Rev Neurosci. 2012;13:225-39.

10. Plum $L$, Belgardt BF, Bruning JC. Central insulin action in energy and glucose homeostasis. J Clin Invest. 2006;116:1761-6.

11. Benarroch EE. Insulin-like growth factors in the brain and their potential clinical implications. Neurology. 2012;79:2148-53.

12. de la Monte SM, Wands JR. Review of insulin and insulin-like growth factor expression, signaling, and malfunction in the central nervous system: relevance to Alzheimer's disease. J Alzheimers Dis. 2005;7:45-61.

13. Ghasemi R, Dargahi L, Haeri A, Moosavi M, Mohamed Z, Ahmadiani A. Brain insulin dysregulation: implication for neurological and neuropsychiatric disorders. Mol Neurobiol. 2013;47:1045-65.

14. Wang L, Liu G, He M, Shen L, Shen D, Lu Y, et al. Increased insulin receptor expression in anterior temporal neocortex of patients with intractable epilepsy. J Neurol Sci. 2010;296:64-8.

15. Jiang G, Wang W, Cao Q, Gu J, Mi X, Wang K, et al. Insulin growth factor-1. (IGF-1) enhances hippocampal excitatory and seizure activity through IGF-1 receptor-mediated mechanisms in the epileptic brain. Clin Sci. 2015;129(12):1047-60.

16. Mulvihill MJ, Cooke A, Rosenfeld-Franklin M, Buck E, Foreman K, Landfair $D$, et al. Discovery of OSI-906: a selective and orally efficacious dual inhibitor of the IGF-1 receptor and insulin receptor. Future Med Chem. 2009;1:1153-71.

17. Kruger DT, Alexi X, Opdam M, Schuurman K, Voorwerk L, Sanders J, et al. IGF-1R pathway activation as putative biomarker for linsitinib therapy to revert tamoxifen resistance in ER-positive breast cancer. Int J Cancer. 2020;146(8):2348-59.

18. Lamhamedi-Cherradi SE, Menegaz BA, Ramamoorthy V, Vishwamitra D, Wang Y, Maywald RL, et al. IGF-1R and mTOR Blockade: Novel Resistance Mechanisms and Synergistic Drug Combinations for Ewing Sarcoma. J Natl Cancer Inst. 2016;108(12):djw182.

19. Pitkanen A, Kharatishvili I, Karhunen H, Lukasiuk K, Immonen R, Nairismagi J, et al. Epileptogenesis in experimental models. Epilepsia. 2007;48(Suppl 2):13-20.

20. Raol YH, Brooks-Kayal AR. Experimental models of seizures and epilepsies. Prog Mol Biol Transl Sci. 2012;105:57-82.

21. Brandt C, Tollner K, Klee R, Broer S, Loscher W. Effective termination of status epilepticus by rational polypharmacy in the lithium-pilocarpine model in rats: Window of opportunity to prevent epilepsy and prediction of epilepsy by biomarkers. Neurobiol Dis. 2015;75:78-90.

22. Racine RJ. Modification of seizure activity by electrical stimulation. II Motor seizure Electroencephalogr Clin Neurophysiol. 1972;32:281-94.

23. Jiang G, Pu T, Li Z, Zhang X, Zhou R, Cao X, et al. Lithium affects rat hippocampal electrophysiology and epileptic seizures in a dose dependent manner. Epilepsy Res. 2018;146:112-20.

24. Byrnes KR, Wilson CM, Brabazon F, von Leden R, Jurgens JS, Oakes TR, et al. FDG-PET imaging in mild traumatic brain injury: a critical review. Front Neuroenergetics. 2014;5:13.

25. Cardoso S, Santos RX, Correia SC, Carvalho C, Santos MS, Baldeiras I, et al. Insulin-induced recurrent hypoglycemia exacerbates diabetic brain mitochondrial dysfunction and oxidative imbalance. Neurobiol Dis. 2013;49:1-12.

26. Rahman S. Pathophysiology of mitochondrial disease causing epilepsy and status epilepticus. Epilepsy Behav. 2015;49:71-5.

27. Puzanov I, Lindsay CR, Goff L, Sosman J, Gilbert J, Berlin J, et al. A phase I study of continuous oral dosing of OSI-906, a dual inhibitor of insulin-like growth factor- 1 and insulin receptors, in patients with advanced solid tumors. Clin Cancer Res. 2015;21(4):701-11.

28. Lord LD, Expert P, Huckins JF, Turkheimer FE. Cerebral energy metabolism and the brain's functional network architecture: an integrative review. J Cereb Blood Flow Metab. 2013;33:1347-54.

29. Paz JT, Huguenard JR. Microcircuits and their interactions in epilepsy: is the focus out of focus? Nat Neurosci. 2015;18:351-9.

30. Deyev IE, Popova NV, Serova OV, Zhenilo SV, Regoli M, Bertelli E, et al. Alkaline pH induces IRR-mediated phosphorylation of IRS-1 and actin cytoskeleton remodeling in a pancreatic beta cell line. Biochimie. 2017;138:62-9. 
31. Yuen AW, Sander JW. Impaired mitochondrial energy production: the basis of pharmacoresistance in epilepsy. Med Hypotheses. 2011;77:536-40.

32. Belanger M, Allaman I, Magistretti PJ. Brain energy metabolism: focus on astrocyte-neuron metabolic cooperation. Cell Metab. 2011;14:724-38.

33. Di Liberto V, van Dijk RM, Brendel M, Waldron AM, Moller C, Koska I, et al. Imaging correlates of behavioral impairments: An experimental PET study in the rat pilocarpine epilepsy model. Neurobiol Dis. 2018;118:9-21.

34. Hiragi T, Ikegaya Y, Koyama R. Microglia after Seizures and in Epilepsy. Cells. 2018;7(4):26.

35. Yang H, Shan W, Zhu F, Wu J, Wang Q. Ketone Bodies in Neurological Diseases: Focus on Neuroprotection and Underlying Mechanisms. Front Neurol. 2019;10:585
36. Li, RJ, Liu, Y, Liu, HQ, Li, J. Ketogenic diets and protective mechanisms in epilepsy, metabolic disorders, cancer, neuronal loss, and muscle and nerve degeneration. J. Food Biochem. 2020;44(3):e13140.

37. de Souza Neves G, Dos Santos Lunardi M, Papini Gabiatti M, Kurrle Rieger Venske, D, Ribeiro LC, Lin K, et al. Cardiometabolic risk and effectiveness of the modified Atkins Ketogenic Diet for adult patients with pharmacoresistant epilepsies in a middle-income country. Epilepsy Res. 2020;160:106280.

38. von Mehren M, George S, Heinrich MC, Schuetze SM, Yap JT, Yu JQ, et al. Linsitinib (OSI-906) for the Treatment of Adult and Pediatric Wild-Type Gastrointestinal Stromal Tumors, a SARC Phase II Study. Clin Cancer Res. 2020;26:1837-45.
Ready to submit your research? Choose BMC and benefit from:

- fast, convenient online submission

- thorough peer review by experienced researchers in your field

- rapid publication on acceptance

- support for research data, including large and complex data types

- gold Open Access which fosters wider collaboration and increased citations

- maximum visibility for your research: over $100 \mathrm{M}$ website views per year

At BMC, research is always in progress.

Learn more biomedcentral.com/submissions 